Ye.I. Baida, M. Clemens, B.V. Klymenko, O.G. Korol, P.Ye. Pustovoitov

\title{
APPLICATION OF THE COMPUTING ENVIRONMENT MAPLE TO THE CALCULATION OF THE DYNAMICS OF THE ELECTROMAGNETS IN THE COMPLICATED SYSTEMS OF FORCED CONTROL
}

Загальний опис теми дослідження. Роздлядається запропонована авторами методика розрахунку динаміки електромагнітів, щцо працюють у складних форсованих системах. Подібні форсовані електромагніти иироко застосовуються в електромеханічних комутаційних апаратах, зокрема у вакуумних контакторах, для змениення їх розмірів, сиоживання енераї̈ та для підвищення швидкодї̈, ще свідчить про актуальність даної теми. Математична модель динаміки форсованої електромагнітної системи, ци враховус особливості поведінки у нестаціонарних процесах ї̈ окремих елементів -механічної системи, магнітного та електричного кіл $з$ урахуванням взаємодї електромагніта 3 пристроєм керування під час спрацьовування апарата, містить певні ознаки наукової новизни $i$ с метою статті. Методика розрахунку динаміки форсованих електромагнітів застосовує математичний пакет Марlе. В основу розрахунку покладено математичну модель, яка представляє собою систему нелінійних диференційних рівнянь магнітного і електричного кіл, доповнених рівняннями руху елементів механічнӧ системи. Застосування пакету Марlе, який багато в чому бере на себе складноці математичного опису різних процесів, автоматично здійснюючи дуже складні і громіздкі математичні перетворення, дозволяє, уникаючи складних процесів вибору способу чисельного інтегрування, програмування складних й громіздких рівнянь та процедур ӥх чисельного інтегрування, отримувати результати розрахунків у зручній табличній та/або графічній формі, ццо свідчить про практичну значущість даної роботи. Наведені у статті результати зіставлення розрахунків з опублікованими раніше експериментальними даними, свідчть про високу ефективність запропонованих моделей та методик. Бібл. 10 , рис. 6.

Ключові слова: електромагніти, динаміка, форсоване керування, комутаційні апарати, вакуумні контактори, математичний пакет Maple.

Общее описание темы исследования. Рассматривается предложенная авторами методика расчета динамики электромагнитов, работающих в сложных форсированных системах. Подобные форсированные электромагниты широко применяются в электромеханических коммутационных аппаратах, в частности в вакуумных контакторах, для уменьшения их размеров, потребления энергии и для повышения быстродействия, что свидетельствует об актуальности данной темы. Математическая модель динамики форсированной электромагнитной системы, учитывающая особенности поведения в нестационарных процессах ее отдельных элементов - механической системы, магнитной и электрической цепей с учетом взаимодействия электромагнита с устройством управления при срабатывании аппарата, содержит определенные признаки научной новизны и является целью статьи. Методика расчета динамики форсированных электромагнитов применяет математический пакет Марlе. В основу расчета положена математическая модель, которая представляет собой систему нелинейных дифференциальных уравнений магнитного и электрического кругов, дополненных уравнениями движения элементов механической системы. Применение пакета Марlе, который во многом берет на себя сложности математического описания различных процессов, автоматически осуществляя очень сложные и громоздкие математические преобразования, позволяет, избегая сложных процессов выбора способа численного интегрирования, программирование сложсных и громоздких уравнений и процедур их численного интегрирования, получать результаты расчетов в удобной табличной и/или графической форме, что свидетельствует о практической значимости данной работь. Приведенные в статье результаты сопоставления расчетов с опубликованными ранее экспериментальньми данными, свидетельствуют о высокой эффективности предложсенных моделей и методик. Библ. 10 , рис. 6.

Ключевые слова: электромагниты, динамика, форсированное управление, коммутационные аппараты, вакуумные контакторы, математический пакет Maple.

Introduction. DC electromagnets are simpler in design than the $\mathrm{AC}$ electromagnets as they have higher reliability and durability. In terms of initial traction force, size and mass, however, they lose significantly in comparison to the the AC electromagnets (which are actually forced electromagnets), because during the operation of the electromagnet, the currents in their windings exceed (ten times or more) the values of currents that are in the windings after the operation of the electromagnet. Forced control of DC electromagnets essentially means that during operation a current flows through a winding, whose value significantly exceeds the current permissible under longterm heating, is used to increase the traction force during operation and to increase the speed of the apparatus. After operation, the current in the winding and, accordingly, its magnetomotive force (MMF) are reduced, but the armature of the electromagnet remains in the final (brought) state, since, at small gaps, the traction force is usually superfluous even at small values of MMF.
Forced electromagnetic systems (FEMS) [1] are widely used in drive systems of low and medium voltage electromechanical switching devices, in particular in contactors, which execute switching operations (switching on and off) the main circuits of powerful electric motors and some other objects.

The FEMS usually includes the electromagnetic mechanism $(E M M)$ - the main contact module and the actuator, which provides the execution of switching operations by contacts (in contactors, the actuator's role is most often performed by a forced unpolarized electromagnet with a rotating spring) and a control device (CD) that performs changes in the windings' control circuit to provide the required values of currents both during operation and in the final state. Note, that in the AC electromagnet which is actually forced, since during the operation the current in the winding is much greater than the current in the final state, the values of the current change without any $\mathrm{CD}$ due to the difference in the values of the inductance in the released and final states). 
When designing switching devices with FEMS, it is necessary to take into account the interaction of the electromagnet with the control device during the operation of the apparatus. Therefore, it is necessary to calculate the dynamics of the electromagnet taking into account the action of the CD. There is a large number of publications devoted to the methods of calculating the dynamics of electromagnets, some of which are listed in references [2 - 9]. Nonetheless, in our opinion, insufficient attention is given to the issue of the interaction of the forced electromagnet with a CD taking into account the large variety of existing CDs and some features of operation of forced electromagnets in switching devices.

The goal of the work is to describe the mathematical model of FEMS dynamics, which takes into account peculiarities of behavior in switching devices of individual elements of FEMS during transients, as well as to build a technique for calculating the dynamics of forced electromagnets using the computing environment Maple.

Mathematical model. The calculation of the FEMS dynamics, where the electromagnet is only a part of the control system that contains the power source, the mechanical system, the forced control device and the electromagnet itself, is reduced to a solution of coupled differential equations. These describe the transients in the circuits of the windings and in the circuits of the forced control device of these windings, transients in magnetic circuits of electromagnets taking into account the effect of eddy currents. They also describe the dynamics of the moving part of the switching device, namely, the armature of the electromagnet, the main contacts of the apparatus, mechanical parts that connect armature with moving contacts (levers, rods, springs, etc.). In many cases, forced control systems are designed so that, when the switching device is operated, the circuit diagrams of the windings are automatically changed if there are several windings or if there are certain changes in the circuits of the forced control device. In the process of performing the on and off operation of the device, also the mass (the moment of inertia) of the moving system can significantly change. If the switching of the main circuits uses vacuum interrupters, the process of movement is significantly affected by bellows and the actual vacuum, which "prevents" the opening of the contacts, pulling the moving contact to the fixed one. All of the abovementioned factors must be taken into account by creating separate fragments of the mathematical model of the dynamics of the electromagnet in the composition of the forced control system, i.e., writing the equation for transients in the mechanical system, as well as in the magnetic and electric circuits of the forced electromagnetic system.

Transients in the mechanical system of the switching device. Kinematics of switching devices in many cases are built so that the part of moving elements carries translational motion, and the other part carries rotary motion (Fig. 1). Since the angles of rotation of moving parts in actual apparatus are relatively small and usually do not exceed $10-15^{\circ}$, a rotating motion with a slight error can be reduced to a translational motion relative to an element adopted as a basic one. Such element may be, for example, an actuator whose armature moves progressively along the axis of the actuator, which is at a distance $r_{\mathrm{a}}$ from the axis of rotation $\mathrm{O}$ of the lever, to which other parts of the switching device are attached and which operate at different distances (shoulders) from the axis O. From the initial armature position the path $s$ passed by the actuator is measured. In calculating the dynamics of motion reduced to the motion of the base element (in our case, to the actuator's armature), the masses of parts moving at different distances from the $\mathrm{O}$ axis must be replaced by reduced masses in accordance with the condition of maintaining the moment of inertia. For example, the reduced mass $m_{\mathrm{d}}^{\prime}$ of the part with mass $m_{\mathrm{d}}$ acting at distance $r_{\mathrm{d}}$ from the $\mathrm{O}$ axis is given by the formula:

$$
m_{\mathrm{d}}^{\prime}=m_{\mathrm{d}} \cdot r_{\mathrm{d}}^{2} / r_{\mathrm{a}}^{2} \text {. }
$$

If the moment of inertia $J$ of some part, for example of the lever shown in Fig. 1, is known, then the calculation of its reduced mass is carried out according to the formula:

$m_{\mathrm{J}}^{\prime}=J / r_{\mathrm{a}}^{2}$.

Thus, the actuator's mass reduced to the axis of the actuator's motion for the fragment shown in Fig. 1 will be equal to:

$m_{\mathrm{a}}^{\prime}=m_{\mathrm{a}}+m_{\mathrm{d}} \cdot r_{\mathrm{d}}^{2} / r_{\mathrm{a}}^{2}+J / r_{\mathrm{a}}^{2}$.

The forces that counteract the movement of the actuator's armature must also be replaced by reduced forces, which are calculated in accordance with the condition of maintaining the moment of force. For example, the force $F_{\mathrm{s}}$ of a spring acting at a distance $r_{\mathrm{s}}$ from the $\mathrm{O}$ axis in the calculation of the dynamics of the actuator's armature motion should be replaced by the reduced force

$$
F_{\mathrm{s}}^{\prime}=F_{\mathrm{s}} \cdot r_{\mathrm{s}} / r_{\mathrm{a}} \text {. }
$$

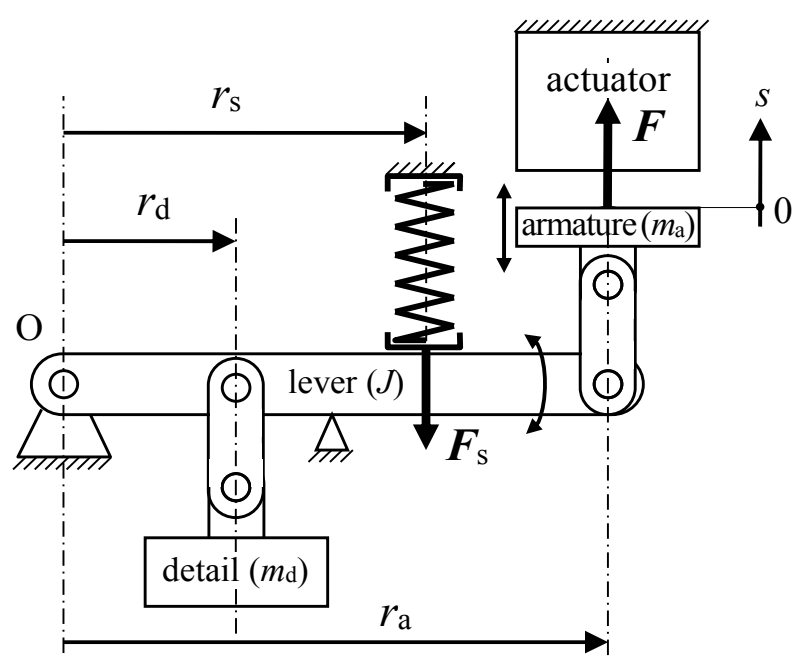

Fig. 1. A fragment of the mechanical system of the switching device

A characteristic feature of electromechanical switching devices is the gradual nature of the forces opposing the movement of the actuator's armature as well as the gradual nature of the change in the mass of moving parts due to the peculiarities of the kinematics of these devices (Fig. 2). 


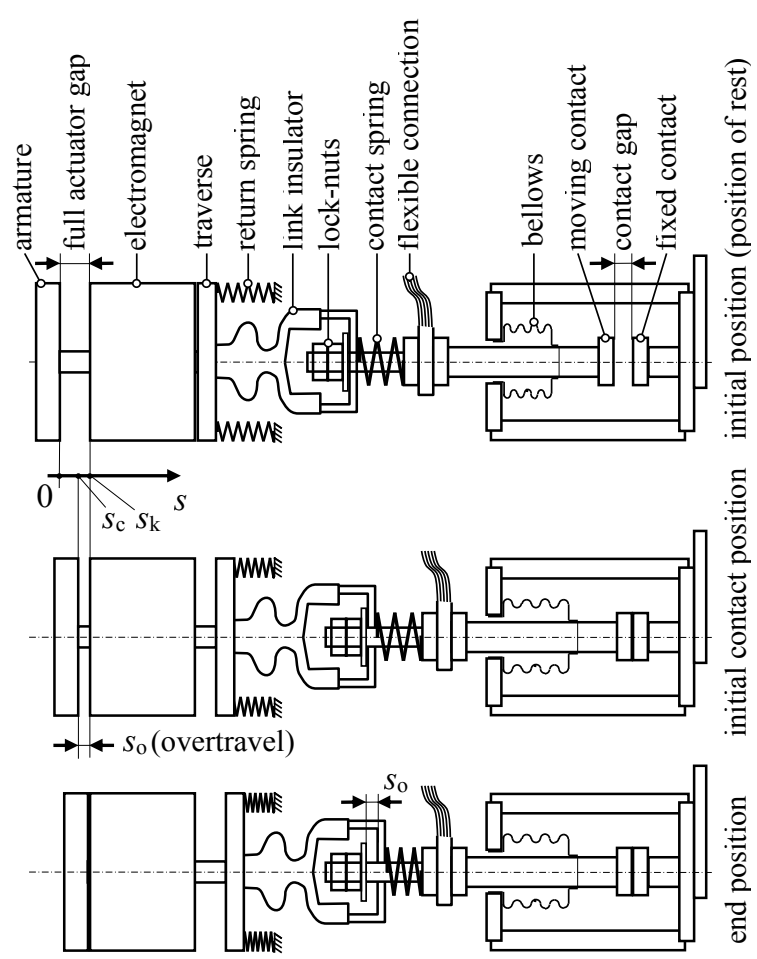

Fig. 2. Kinematic circuits of the switching device in three characteristic positions

During the operation of the switching device, two stages of the motion of its mechanical system can be observed: the first stage - from the initial position (position of rest) to the initial contact position $\left(0<s<s_{\mathrm{c}}\right)$ and the second stage from the of initial contact position to the end position $\left(s_{\mathrm{c}}<s\right.$ $<s_{\mathrm{k}}$ ). At the first stage, the reduced mass of moving parts is comprised of the reduced mass of the mechanical system $m_{\mathrm{v}}$ and a reduced mass of moving contacts $m_{\mathrm{c}}$. At the second stage, the moving contacts stop - they are faced with fixed contacts, therefore the reduced mass of moving parts is almost abruptly reduced to the value $m_{\mathrm{v}}$

$m= \begin{cases}m_{\mathrm{v}}+m_{\mathrm{c}} & \text { at } s<s_{\mathrm{c}} \\ m_{\mathrm{v}} & \text { at } s \geq s_{\mathrm{c}} .\end{cases}$

Thus, when the switching device operates, there is a motion with a variable mass, which is described by such a system of differential equations:

$\frac{\mathrm{d}}{\mathrm{d} t}(m \cdot v)=F-F_{\mathrm{r}}$

$\frac{\mathrm{d} s}{\mathrm{~d} t}=v$,

where $F$ is the electromagnetic force providing the actuator's movement, $F_{\mathrm{r}}$ is the reduced force that counteracts the movement of the actuator's armature, $v$ is the speed of the actuator's armature, $s$ is the path passed by the armature from the beginning of the movement, $t$ is time.

After performing the differentiation operation in (6), we obtain:

$m \cdot \frac{\mathrm{d} v}{\mathrm{~d} t}+\frac{\mathrm{d} m}{\mathrm{~d} s} \cdot v^{2}=F-F_{\mathrm{r}} ;$

Function (5) is discontinuous, at its differentiation there are pulsed functions which makes it practically impossible to carry out further calculations using (8), therefore we have applied the approximation of this function with the use of hyperbolic tangent. As a result, the following expression is obtained:

$m=m_{\mathrm{v}}+m_{\mathrm{c}} \cdot\left(1-\operatorname{th}\left(A \cdot\left(s-s_{\mathrm{c}}\right)\right)\right) / 2$,

where $A$ is a suitably chosen large constant number.

The function (9) is smooth, allowing for a differentiation operation, but the mathematical expression of the derivative is very cumbersome, but the Maple computing environment does not require the programmer to perform transformations related to bringing the equations to a canonical form: this code performs all the required complex algebraic transformations itself. In the Maple environment it is only necessary to write expressions (7), (8), (9) and write the command that provides the solution of the system of differential equations.

The force $F_{\mathrm{r}}$, which counteracts the movement of the actuator's armature is formed due to the action of the rotary and contact springs, the action of forces of the deformation of the bellows, the action of vacuum and friction. This force has a step-by-step nature, but since it does not require differentiation, the corresponding expression in the code can be written as follows:

$F_{\mathrm{r}}= \begin{cases}F_{1}+\frac{F_{2}-F_{1}}{s_{\mathrm{c}}} \cdot s & \text { at } s<s_{\mathrm{c}} ; \\ F_{3}+\frac{F_{4}-F_{3}}{s_{\mathrm{k}}-s_{\mathrm{c}}} \cdot\left(s-s_{\mathrm{c}}\right) & \text { at } s \geq s_{\mathrm{c}},\end{cases}$

where $F_{1}, F_{2}$ are the values of reduced countermeasures force, respectively, at the beginning and end of the first stage of the movement of the mechanical system of the apparatus; $F_{3}, F_{4}$ are the values of reduced countermeasure force, respectively, at the beginning and end of the second stage of the movement of the mechanical system of the apparatus.

The difference between $F_{3}$ and $F_{2}$ must be equal to the sum of the values of the initial contact forces at all poles of the apparatus.

Transients in the magnetic circuit. A mathematically rigorous calculation of transient magnetic field can be carried out by solving a system of nonlinear partial differential equations featuring the magnetic vector potential $\boldsymbol{A}$. Similar problems are solved relatively simply for $2 \mathrm{D}$ plane-parallel or plane-meridian fields [9]. In such cases, where the total costs of simulating high-fidelity 3D models is inacceptably high and even 2D models are not applicable, alternative techniques may need to be used including those that have proven themselves well in the past. Such a technique for magnetic circuits is a method of electromagnetic analogies, complemented by new features provided by modern software products, in particular the Maple code.

Figure 3 shows an substitution circuit of the magnetic circuit of a double-rod electromagnet used in the vast majority of vacuum and low voltage contactors. In contrast to the well-known circuit, which is given in many sources, in particular in [1], in this circuit, on each section of the core, divided along the axis into $n$ equal parts, the «eddy» MMFs that arise during transients are introduced:

$\Delta F_{\mathrm{mcj}}=\Delta G_{\mathrm{c}} \cdot \frac{\mathrm{d} \Phi_{j}}{\mathrm{~d} t}, j=1,2, \ldots, n$. 


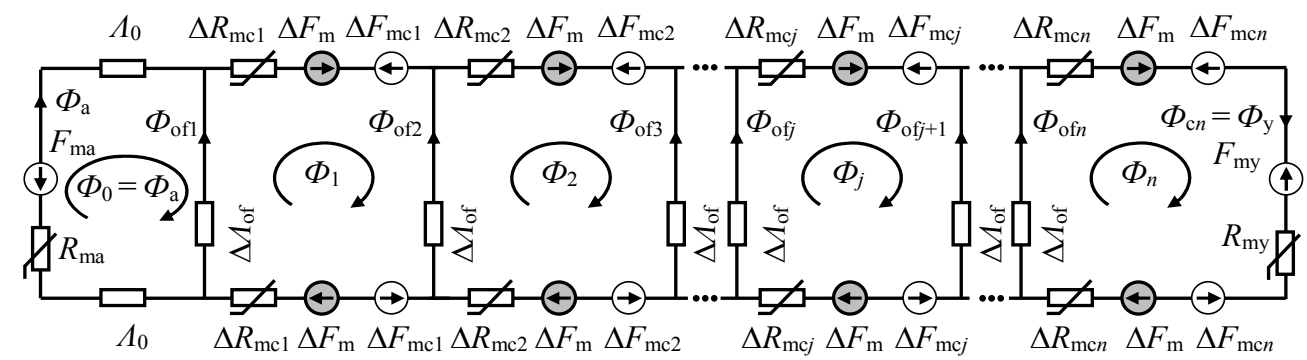

Fig. 3. Substitution circuit of the magnetic circuit of a double-rod electromagnet taking into account the effect of eddy currents in cores, armature and yoke

«Eddy» MMFs also appear in the branches of the substitution circuit corresponding to the sections of the armature and yoke:

$$
F_{\text {ma(y) }}=G_{\mathrm{a}(\mathrm{y})} \cdot \frac{\mathrm{d} \Phi_{\mathrm{a}(\mathrm{y})}}{\mathrm{d} t} .
$$

In (11), (12) and in Fig. 3 the following notation is used: $\Delta G_{\mathrm{c}}$ is the electrical conductance of the equivalent shortcircuited circuit in the eddy current path that arises in the area with the number $j$ divided into $n$ equal parts of the core of length $l_{\mathrm{c}}, G_{\mathrm{a}(\mathrm{y})}$ is the electrical conductance of the equivalent short-circuited circuit in the eddy current path generated in the armature, $\Phi_{i}$ is the magnetic flux through the area of the core with the number $j$. The variables $\Phi_{\mathrm{a}}, \Phi_{\mathrm{y}}$ are magnetic fluxes through the armature and the yoke, respectively. The variable $F_{\mathrm{m}}$ denotes the MMF of one coil ${ }^{1}$, $\Delta F_{\mathrm{m}}$ is the MMF of one part of the coil, divided into $n$ equal parts $\left(\Delta F_{\mathrm{m}}=F_{\mathrm{m}} / n\right), R_{\mathrm{ma}}, R_{\mathrm{my}}$ are the magnetic resistance of the armature and yoke, respectively. The variable $\Delta R_{\mathrm{mc} j}$ is the magnetic resistance of the core section with the number $j, \Lambda_{0}$ is the magnetic conductivity of the working gap, $\Delta \Lambda_{\text {of }}$ is the magnetic conductivity of outflow which falls on one area of the core. The variables $F_{\mathrm{ma}}, F_{\mathrm{my}}$ describe the «eddy» MMFs arising respectively in the armature and yoke; $F_{\mathrm{mc} i}$ is the «eddy» MMF that occurs in the core section with the number $j$.

The calculation of the magnetic resistances $\Delta R_{\mathrm{mc} i}, R_{\mathrm{ma}}$, $R_{\mathrm{my}}$, the electrical conductances $\Delta G_{\mathrm{c}}, G_{\mathrm{a}}, G_{\mathrm{y}}$, as well as the magnetic conductance of outflow $\Delta \Lambda_{\mathrm{of}}$ is carried out according to the formulas:

$$
\begin{aligned}
& R_{\mathrm{mcj}}=l_{\mathrm{c}} /\left(n \cdot \mu\left(\Phi_{j} / S_{\mathrm{c}}\right) \cdot S_{\mathrm{c}}\right), \\
& R_{\mathrm{ma}(\mathrm{y})}=l_{\mathrm{a}(\mathrm{y})} /\left(\mu\left(\Phi_{\mathrm{a}(\mathrm{y})} / S_{\mathrm{a}(\mathrm{y})}\right) \cdot S_{\mathrm{a}(\mathrm{y})}\right), \\
& \Delta G_{\mathrm{c}}=l_{\mathrm{c}} /\left(n \cdot 8 \cdot \pi \cdot \rho_{s}\right), \\
& G_{\mathrm{a}(\mathrm{y})}=l_{\mathrm{a}(\mathrm{y})} /\left(16 \cdot \rho_{s} \cdot\left(c_{\mathrm{a}(\mathrm{y})} / b_{\mathrm{a}(\mathrm{y})}+b_{\mathrm{a}(\mathrm{y})} / c_{\mathrm{a}(\mathrm{y})}\right)\right), \\
& \Delta \Lambda_{\mathrm{of}}=\lambda \cdot l_{\mathrm{c}} / n,
\end{aligned}
$$

where $\lambda$ is the specific magnetic conductivity of outflow; in the case of two parallel circular cores we have:

$$
\lambda=\mu_{0} \cdot \frac{\pi}{\ln \left(l / d_{\mathrm{c}}+\sqrt{\left(l / d_{\mathrm{c}}\right)^{2}-1}\right)} .
$$

The conductances of working gaps can be calculated by the method of enlarged field tubes:

\footnotetext{
${ }^{1}$ Electromagnet, the circuit of which is shown in Fig. 3, is doublerod, so it has two identical coils, each of which can have one or more windings. In the first case, the MMF of the coil is equal to the MMF of its winding, in the second case, the MMF of the coil is equal to the sum of MMFs of windings with different number of turns and different currents in them.
}

$$
\Lambda_{0}=\frac{\mu_{0}}{2} \cdot\left(\frac{\pi \cdot d_{\mathrm{p}}^{2}}{4 \cdot \delta}+1.63 \cdot d_{\mathrm{p}}+1.232 \cdot \delta+l_{\mathrm{p}} \cdot\left(\frac{4 \cdot d_{\mathrm{p}}}{2 \cdot \delta+l_{\mathrm{p}}}+2\right)\right) .
$$

In (13)-(19) we indicate: $\mu$ is the relative magnetic permeability, i.e., a nonlinear function (for a specific magnetic material; this function, depending on the magnetic flux density, is usually given in tabular form.), $d_{\mathrm{c}}, S_{\mathrm{c}}$ are the diameter and cross-sectional area of the core, $d_{\mathrm{p}}, S_{\mathrm{p}}, l_{\mathrm{p}}$ are the diameter, cross-sectional area and thickness of the pole tip, $l$ is the distance between the axes of the cores and $\delta$ is the working air gap between the pole tip and armature.

The calculation of the magnetic circuit makes it possible to determine the magnetic fluxes, and thus the traction force created by the electromagnet. On the other hand, the traction power determines the movement of the mechanical system, therefore, processes in the mechanical system and in the magnetic circuit are interrelated. These processes, however, are inextricably coupled with processes in electrical circuits, which we consider below.

Transients in the electric circuit. In this paper, choosing from a lot of existing systems of forced control, we consider a system, which is most often used in low and medium voltage contactors (Fig. 4).

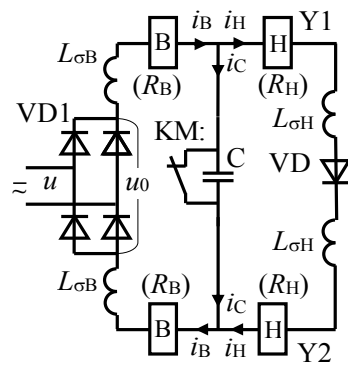

Fig. 4. Principle electrical circuit of a widespread system of forced control that is used in low and medium voltage vacuum contactors and in some SF6 medium voltage contactors [10]; $u$ is the instantaneous value of the nominative voltage of the control circuit; $u_{0}$ is the voltage at the output of the diode bridge

This forced control system provides power supply from a DC or AC source:

$u= \begin{cases}U & \text { for DC; } \\ U_{\mathrm{m}} \cdot \sin (2 \cdot \pi \cdot f \cdot t+\alpha) & \text { for AC. }\end{cases}$

where $f$ is the frequency, $\alpha$ is the initial phase.

Thus, the voltage at the output of the diode bridge can be constant or rectified, but in any case, the voltage reduction due to its drop in the bridge diodes should be taken into account, which can be especially significant when powered from the network of ultra-low voltage: $u_{0}=|u|-2 \cdot u_{\mathrm{d}}\left(i_{\mathrm{B}}\right)$.

In this paper, the nonlinear characteristic of the diode is replaced by a piecewise linear dependence: a very large resistance to $R_{\text {rd }}$ at negative (reverse) currents, at relatively large positive currents of the voltage drop on the diode is 
considered to be a constant value of $U_{\mathrm{d} 0}$, and at relatively small positive currents smaller than some value $I_{0}$, the diode is considered as a resistor with resistance $U_{\mathrm{d} 0} / I_{0}$ :

$$
u_{\mathrm{d}}= \begin{cases}R_{\mathrm{rd}} \cdot i & \text { at } i<0 \\ U_{\mathrm{d} 0} \cdot i / I_{0} & \text { at } 0 \leq i<I_{0} \\ U_{\mathrm{d} 0} & \text { at } i>I_{0} .\end{cases}
$$

Another feature of this system of forced control - it involves the use of an electromagnet with two coils, each of which has two windings - booster $(\mathrm{B})$ and holding $(\mathrm{H})$. Booster windings are wound by a wire of a relatively large diameter and have a large MMF. These windings operate short-term - during the operation of the electromagnet, when the control auxiliary contact KM is closed, and as a result they are connected in series, connected to the power supply to the control circuit, and generate the MMF that is sufficient to allow the contactor to operate. After operation of the contactor, the contact $\mathrm{KM}$ opens and the retaining windings are connected in series with the booster windings. These are wound with a relatively thin wire. As a result, they have considerably greater resistance and considerably less MMF, which at a small gap is sufficient to hold the armature of the electromagnet in the pulled state. Capacitor $\mathrm{C}$ provides efficient arc extinguishing at interruption of high current that passed through the booster windings, and the diode VD2 prevents countercurrent in the holding windings when the contactor is braked, and in some cases even blocks the operation of the apparatus.

This electric circuit is often considered to be too complicated for programming, but its description is much simpler if the parallel connection of the capacitor $\mathrm{C}$ with the auxiliary control contact $\mathrm{KM}$, which is closed when the coordinate $s$ of the armature stroke does not exceed the value of the coordinate $s_{\mathrm{a}}$ at which the opening of this contact occurs, to replace with one capacitor with very high capacitance $C_{\mathrm{M}}$ when $s \leq s_{\mathrm{a}}$, and at $s>s_{\mathrm{a}}$ the capacitance of this capacitor becomes equal to its nominal value $C_{0}$ :

$C= \begin{cases}C_{\mathrm{M}} & \text { at } s \leq s_{\mathrm{a}} ; \\ C_{0} & \text { at } s>s_{\mathrm{a}} .\end{cases}$

In this case, we obtain the following differential equations for electric circuits:

$$
\begin{aligned}
& u_{0}=2 \cdot R_{\mathrm{B}} \cdot i_{\mathrm{B}}+2 \cdot L_{\sigma \mathrm{B}} \cdot \frac{\mathrm{d} i_{\mathrm{B}}}{\mathrm{d} t}+2 \cdot N_{\mathrm{B}} \cdot \frac{\mathrm{d} \Phi_{0}}{\mathrm{~d} t}+u_{\mathrm{C}} ; \\
& u_{\mathrm{C}}=2 \cdot R_{\mathrm{H}} \cdot i_{\mathrm{H}}+2 \cdot L_{\sigma \mathrm{H}} \cdot \frac{\mathrm{d} i_{\mathrm{H}}}{\mathrm{d} t}+2 \cdot N_{\mathrm{H}} \cdot \frac{\mathrm{d} \Phi_{0}}{\mathrm{~d} t}+u_{\mathrm{d}}\left(i_{\mathrm{H}}\right) ; \\
& C \cdot \frac{\mathrm{d} u_{\mathrm{C}}}{\mathrm{d} t}=i_{\mathrm{B}}-i_{\mathrm{H}},
\end{aligned}
$$

In these three equations, the unknown values are currents $i_{\mathrm{B}}, i_{\mathrm{H}}$, voltage $u_{\mathrm{C}}$ and magnetic flux $\Phi_{0}$, but the latter is determined when solving the corresponding magnetic circuit equation.

Note that the Maple code does not require representing the task of integrating systems of differential equations in the form of a system solved with respect to the first derivatives. It independently chooses the method and step of integration, as well as independently performs complex algebraic transformations, which makes it an valuable tool for solving complex problems of forced systems dynamics calculation.

\section{Model validation on a full specimen.}

Data of experimental studies of industrial samples of vacuum contactors are presented in one of the previous papers [10], where forced control systems were used as in Fig. 4. In particular, the oscillograms of the dynamic characteristics of the currents in the booster and holding windings were obtained at the power supply of the control system from DC and AC sources. The experimental data were compared with the results of calculations performed using a simplified model of the magnetic circuit, which was considered as a circuit with lumped parameters (Fig. 5).

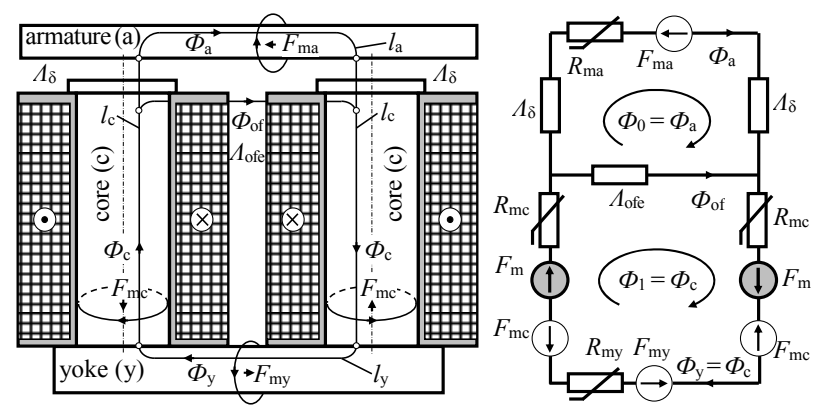

Fig. 5. A sketch of a double-rod magnetic core of the electromagnet and its simplified substitution circuit

The equations compiled for two circuits with magnetic fluxes $\Phi_{0}$ and $\Phi_{1}$ have the following form:

$$
\begin{aligned}
& -\frac{1}{R_{\mathrm{a}}} \cdot \frac{\mathrm{d} \Phi_{0}}{\mathrm{~d} t}=H\left(\Phi_{0} / S_{\mathrm{a}}\right) \cdot l_{\mathrm{a}}+\frac{2 \cdot \Phi_{2}}{\Lambda_{\delta}}-\left(\Phi_{1}-\Phi_{0}\right) / \Lambda_{\text {ofe }} \\
& 2 \cdot i_{\mathrm{B}} \cdot w_{\mathrm{B}}+2 \cdot i_{\mathrm{H}} \cdot w_{\mathrm{H}}-\left(2 \cdot G_{\mathrm{c}}+G_{\mathrm{y}}\right) \cdot \frac{\mathrm{d} \Phi_{1}}{\mathrm{~d} t}= \\
& =H\left(\Phi_{1} / S_{\mathrm{y}}\right) \cdot l_{\mathrm{y}}+2 \cdot H\left(\Phi_{1} / S_{\mathrm{c}}\right) \cdot l_{\mathrm{c}}+\left(\Phi_{1}-\Phi_{0}\right) / \Lambda_{\text {ofe }}
\end{aligned}
$$

The calculations are carried out in accordance with the following input data, the designations of which correspond to those given in Fig. 5 and in explications of the formulas (5), (10) and (11)-(26): $l_{\mathrm{a}}=65 \mathrm{~mm} ; l_{\mathrm{y}}=65 \mathrm{~mm}$; $l_{\mathrm{c}}=59 \mathrm{~mm} ; l=64 \mathrm{~mm} ; d_{\mathrm{c}}=26 \mathrm{~mm} ; d_{\mathrm{p}}=30 \mathrm{~mm} ; \delta=5 \mathrm{~mm}$; $a_{\mathrm{y}}=6 \mathrm{~mm} ; a_{\mathrm{a}}=5 \mathrm{~mm} ; b_{\mathrm{y}}=40 \mathrm{~mm} ; b_{\mathrm{a}}=32 \mathrm{~mm} ; l_{\mathrm{p}}=3 \mathrm{~mm}$; $s_{\mathrm{k}}=\delta ; s_{\mathrm{c}}=3,5 \mathrm{~mm} ; s_{\mathrm{a}}=4,5 \mathrm{~mm} ; m_{\mathrm{v}}=2,2 \mathrm{~kg} ; m_{\mathrm{c}}=0,6 \mathrm{~kg}$; $F_{1}=161 \mathrm{~N} ; F_{2}=172 \mathrm{~N} ; F_{3}=221 \mathrm{~N} ; F_{4}=253 \mathrm{~N} ; L_{\mathrm{\sigma B}}=5 \mathrm{mH}$; $L_{\sigma \mathrm{H}}=18 \mathrm{mH} ; R_{\mathrm{B}}=56 \Omega ; R_{\mathrm{H}}=900 \Omega ; \rho_{\mathrm{s}}=20 \cdot 10^{8} \Omega \cdot \mathrm{m} ;$ $R_{\mathrm{d}}=1 \cdot 10^{8} \Omega ; U_{0}=1 \mathrm{~V} ; I_{0}=1 \mathrm{~A}, C_{\mathrm{M}}=1 \mathrm{~F} ; C_{0}=1 \mu \mathrm{F}$.

The results of some calculations are shown in Fig. 6. These results are plotted directly on the oscillograms, which makes it possible to assess the adequacy of the proposed technique and the high accuracy of the calculations performed.

\section{Conclusions.}

1. Utilization of the computing environment Maple for mathematical modelling of the dynamics of forced electromagnetic systems allows to significantly accelerate the process of simulation, save time and significant material resources, while providing an acceptable accuracy of the results.

2. The adequacy of the developed model is confirmed by experimental studies, which showed a good coincidence of the results of the mathematical and the full-scale experiments, and, characteristically, this coincidence is observed in the conditions of complex shapes of curves of currents in windings. 


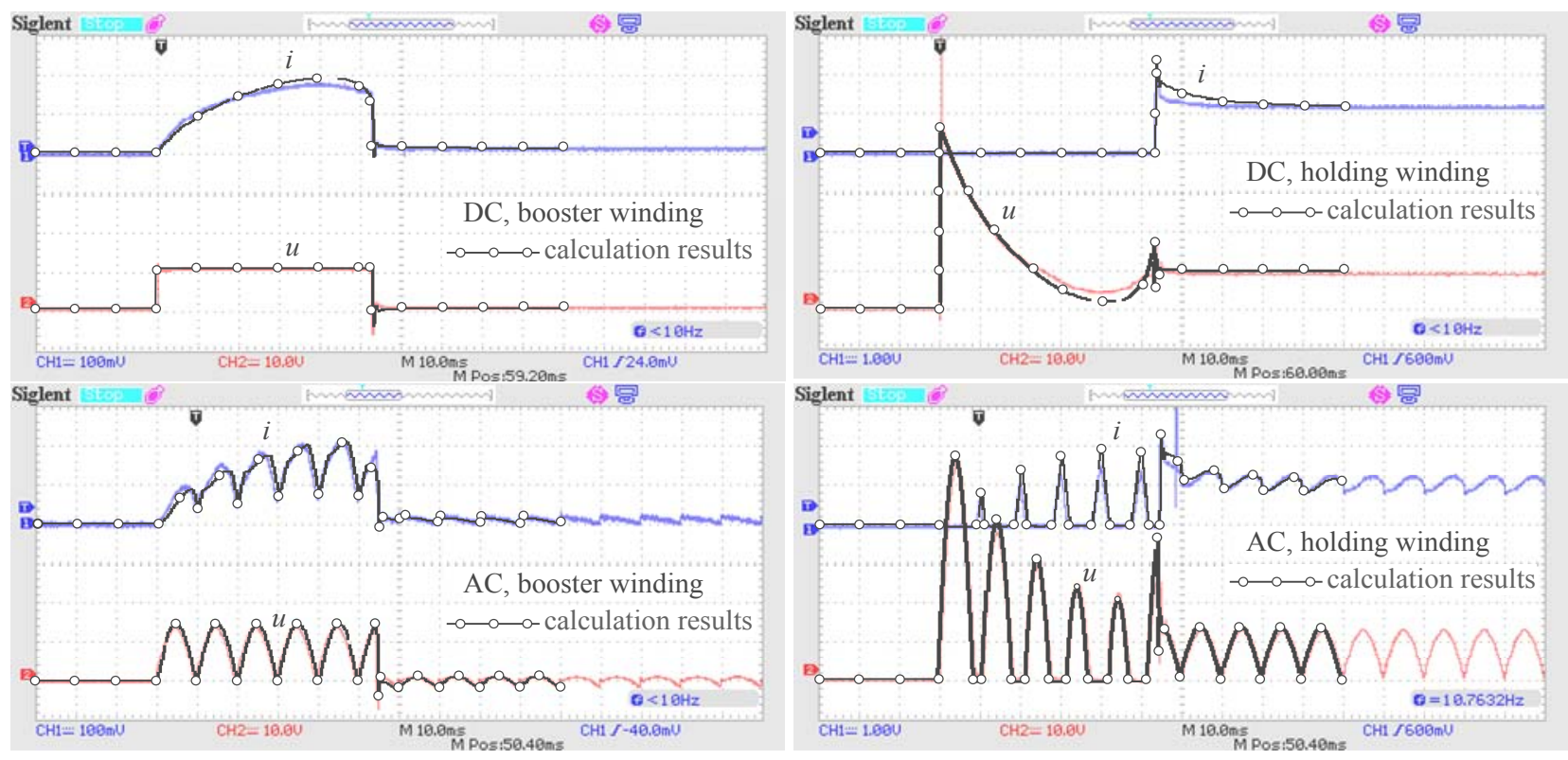

Fig. 6. Comparison of experimental data obtained on industrial samples of vacuum contactors with calculation results using a simplified model of the magnetic circuit, which is considered as a circuit with lumped parameters

\section{REFERENCES}

1. Klymenko B.V. Forced electromagnetic systems. Moscow, Energoatomizdat, 1989. 160 p. (Rus).

2. Koltermann P.I., Assumpção Bastos J.P., Arruda S.R. A Model for Dynamic Analysis of AC Contactor. IEEE Transactions on Magnetics, 1992, vol. 28, no. 2, pp. 1348-1350. doi: 10.1109/20.123941.

3. Nowak L., Demenko A. 3D coupled field-circuit simulation of electromechanical converter dynamics. COMPEL - The international journal for computation and mathematics in electrical and electronic engineering, 1998, vol. 17, no. 4, pp. 439-447. doi: 10.1108/03321649810210613.

4. Wada M., Yoshimoto H., Kitaide Y. Dynamic analysis and simulation of electromagnetic contactors with AC solenoids. IEEE 2002 28th Annual Conference of the Industrial Electronics Society, IECON 02, 5-8 Nov. 2002. doi: 10.1109/iecon.2002.1182829.

5. Ruiz J.-R. R., Espinosa A.G. A Novel Parametric Model for AC Contactors. IEEE Transactions on Magnetics, 2008, vol. 44, no. 9, pp. 2215-2218. doi: 10.1109/tmag.2008.2000544.

6. Li Y., Xia K., Liu W., Li D. Design and simulation anylysis of electromagnetic repulsion mechanism. 2010 IEEE International Conference on Industrial Technology, 2010. pp. 914-918. doi: 10.1109/ICIT.2010.5472562.

7. You Jiaxin, Liang Huimin, Ma Guangcheng, Chen Shuqing, Cai Zhaowen. Research on the dynamic calculation model for a DC solenoid electromagnetic contactor and its contact characteristics in break process. 2015 IEEE 61st Holm Conference on Electrical Contacts (Holm), San Diego, CA, 2015, pp. 191-194. doi: 10.1109/HOLM.2015.7355096.

8. Tatevosian A.S. Dinamika elektromagnitov [Dynamics of electromagnets]. Omsk, Omsk State Technical University Publ., 2016. 148 p. (Rus).

9. Bajda Ye.I., Klymenko B.V., Pantelyat M.G., Yelanskyi Yu.A., Trichet D., Wasselynck G. Peculiarities of calculating the dynamics of high-speed electromagnets using tunable elastic meshes. Book of Abstracts of the 19th International Symposium on Electromagnetic Fields in Mechatronics, Electrical and Electronic Engineering (ISEF'2019), Nancy, France, August 2019, 2 p., accepted.

10. Korol O.G., Klymenko B.V., Yeresko O.V. Investigations of transients in the forced control device for the monostable electromagnet of the vacuum contactor. Bulletin of NTU «KhPI». Series: Problems of Improvement of Electrical Machines and Apparatus. Theory and Practice, 2018, no. 32 (1308), pp. 34-40. doi: 10.20998/2079-3944.2018.32.06. (Ukr).
Received 07.02.2019

Ye.I. Baida ${ }^{1}$, M. Clemens ${ }^{2}$, B.V. Klymenko ${ }^{1}$, O.G. Korol ${ }^{1}$, P.Ye. Pustovoitov ${ }^{1}$

${ }^{1}$ National Technical University «Kharkiv Polytechnic Institute»,

2, Kyrpychova Str., Kharkiv, 61002, Ukraine,

phone+380 57 7076281, e-mail: b.v.klymenko@gmail.com

${ }^{2}$ University of Wuppertal,

Rainer-Gruenter-Straße 21, 42119 Wuppertal, Germany, phone +49 202 439-1924, e-mail: clemens@uni-wuppertal.de

Application of the computing environment Maple to the calculation of the dynamics of the electromagnets in the complicated systems of forced control.

General description of the research topic. The authors propose a technique for calculating the dynamics of electromagnets operating in complex forced systems. Such forced electromagnets are widely used in electromechanical switching devices, in particular in vacuum contactors, to reduce their size, energy consumption and to increase speed, which indicates the relevance of this topic. A mathematical model of the dynamics of a forced electromagnetic system, which takes into account the peculiarities of behavior in transients of its individual elements - the mechanical system, the magnetic and electrical circuits, taking into account the interaction of the electromagnet with a control device when the apparatus is activated, contains certain signs of scientific novelty and is the purpose of the paper. The technique of calculating the dynamics of forced electromagnets uses the computing environment Maple. The calculation is based on a mathematical model, which is a system of nonlinear differential equations of the magnetic and electric circuits, supplemented by the equations of motion of the elements of a mechanical system. The use of the computing environment Maple, applied here to automatically perform the mathematical transformations, allows avoiding the complicated processes of choosing the numerical integration method, programming of complex and cumbersome equations and numerical integration procedures, to obtain results of calculations in convenient tabular and/or graphic form. This specifically indicates the practical significance of this work. The results of the comparison of calculations with previously published experimental data presented in the paper indicate the high efficiency of the proposed models and techniques. References 10, figures 6.

Key words: electromagnets, dynamics, forced control, switching devices, vacuum contactors, computing environment Maple.

How to cite this article:

Baida Ye.I., Clemens M., Klymenko B.V., Korol O.G., Pustovoitov P.Ye. Application of the computing environment Maple to the calculation of the dynamics of the electromagnets in the complicated systems of forced control. Electrical engineering \& electromechanics, 2019, no.3, pp. 18-23. doi: 10.20998/2074-272X.2019.3.03. 